\title{
ISLAM AGAMA KOSMOPOLIT: SOLUSI DERADIKALISASI MEMUPUK SIKAP TOLERANSI
}

\author{
M. Ridlwan Hambali \\ Institut Agama Islam (IAI) Sunan Giri Bojonegoro \\ ridlwan2020@gmail.com
}

\begin{abstract}
Abstrak
"Islam adalah agama rahmat bagi seluruh alam. Islam juga mempunyai nilai-nilai yang universal. Dan karenanya Islam dianggap sebagai agama kosmopolit, yang artinya Islam mempunyai cakupan dan wawasan yang sangat luas melampaui batas-batas etnis budaya dan suku. Tulisan dalam artikel ini bermaksud untuk membuktikan bahwa Islam bisa diterima oleh semua golongan karena nilai-nilai dan cakupan yang ada di dalamnya. Islam tidak pernah membeda-bedakan antara yang kulit hitam dan kulit putih sejak zaman Nabi Muhammad SAW. Dengan wawasan seperti itu diharapkan umat Islam bisa menerima segala bentuk perbedaan sebagai satu hal yang Fitrah atau alami. Karena sesungguhnya perbedaan adalah satu keniscayaan. Dengan sikap itu pula umat Islam diharapkan bisa ikut andil dalam menolak segala bentuk kekerasan dan gerakan radikal sekaligus membantu menumbuhkan sikap toleransi untuk hidup bersama secara lebih damai aman dan bahagia. Semoga tulisan yang pendek ini dapat menggugah hati nurani kita semua untuk bisa memilah dan memilih mana yang baik dan mana yang buruk mana yang perlu dikembangkan dan dilestarikan dan mana yang perlu ditinggalkan dan ditolak."
\end{abstract}

Kata kunci : Islam, Kosmopolit, Deradikalisasi dan Toleransi

\section{Pendahuluan}

Sejarah semarak dan heterogennya aktifitas keilmuan Islam, sejak kemunculannya hingga sekarang adalah salah satu indikasi konkrit atas wujud dari kosmopolitanisme agama Islam. Sekian banyak ragam pemahaman terhadap pesan-pesan agama, yang kelak menjadi beberapa aliran pemikir praktis keagamaan, bisa hidup dan eksis mewarnai perjalanan panjang sejarah peradaban Islam. Meski pada awal kemunculannya sering merupakan reaksi dari sikap ketidak puasan terhadap paham tertentu. Akan tetapi, justru budaya dialektik ilmiyah, yang didasari rasa toleransi yang dalam itulah proses transformasi sosial dalam skala masif bisa kita lihat sepanjang sejarah. Sebagai contoh, muslim tempo dulu, sesuai dengan kapasitas dan substansi keilmuan yang mereka miliki, berbeda-beda dalam memahami pesan agama. Akan tetapi, persamaan prinsip, visi, dan misi (al-mabādi' wa al-ghayāt) antara mereka telah membentuk satu 
sikap toleransi yang utuh. Tidak pernah ada lontaran kecaman, cacian apalagi takfirisasi. Mereka bersatu padu membela Islam. ${ }^{1}$ Fenomena budaya toleransi itu menunjukkan bahwa -disamping konsistensi mereka yang kuat terhadap nilai-nilai etis yang telah diwarisi dari Rasulullahpemahaman mereka terhadap nas-nas agama masih sangat bersih, bagai "mata air" yang senantiasa memberi kesejukan dan kesegaran pada siapa saja yang meminumnya, meski dengan kadar dahaga yang berbeda-beda. Kedekatan mereka dengan masa kenabian sangat membantu dalam menginterpretasikan teks-teks agama. Mereka mengetahui sebab-sebab dan rahasia turunnya wahyu. Sebagai manifestasi dari pangkat "khairul qurun” yang mereka sandang, mereka dengan ikhlas memahami agama sesuai kapasitas dan proporsinya. Pemahaman yang tidak pernah didasarkan pada kepentinga-kepentingan individu; pemahaman yang belum pernah tercemari oleh bias-bias fanatisme kelompok, golongan, atau ideologi.

Hingga datang masa di mana Islam dijadikan sebagai alat kekuasaan. Islam tidak lagi difahami secara komprehensif, akan tetapi dipahami secara parsialistis sebagai legitimasi klaimklaum mereka. Seperti disinggung oleh al-Maududi, bahwa masa itu dimulai pada masa akhirakhir kekhalifahan Usman bin al-'Affan ra. Maududi mensinyalir bahwa masa itu adalah masa dimulainya praktek-praktek paradigma jahiliyah. Praktek takfirisasi juga menjadi tradisi yang sudah membudaya. Dalam satu deskripsinya ia mengatakan:

"Hegomone peradaban Barat telah hadir dimasa kita, membentuk satu paradigma jahiliyah modern. Peradaban yang telah memaksa kita untuk "menuhankan" manusia (dan materi); memutus tali hubungan sesama manusia. Manusia bagai binatang buas saling terkam antar sesama. "Ujian berat” yang dihembuskan oleh Barat itu sebagai dampak dari kemunduran kita sejak beberapa abad. Paradigma jahiliyah itu telah membiasi sistem konstitusional Islam sejak khalifah Usman bin al'Affan ra ?! sampai pada masa Umar bin Abdul Aziz, (yang disinyalir sebagai Khalifah kelima) nilai-nilai agama kembali jalan stabil. Kemudian datang filsafat Yunani, Romawi dan 'Ajam (lain arab) menyusupkan unsur-unsur nilai jahiliyah melalui sains, seni, budaya, dan sosial. Akan tetapi, semua itu tidak membuat lentera Islam padam... kita juga tidak gampang memvonis seseorang kafir. Karena siapa

\footnotetext{
${ }^{1}$ Mahmud Syaltut, "Kata Pengantar", dalam Musthafa al-Syakh'ah, "Islām Bilā Mazāhib”, (Kairo: Dār al-Miṣriyah al-Libnāniyah, 1994), 25.
} 
orang yang telah ber-i'tikat bahwa tuhan itu satu (tauhid) maka ia telah iman. Dan barang siapa memvonis kafir seorang mukmin, maka ia sama dengan membunuhnya.,"2

Suasana kronis yang diilustrasikan al Madudi diatas masih begitu kuatnya mencengkeram dunia Islam saat ini. Sebagai langkah terapi, kita perlu kiranya mengembalikan pemahaman terhadap agama sebagaimana muslim tempo dulu memahaminya; pemahaman agama yang benar dan bersih tanpa teracuni oleh bias-bias peradaban Barat. Dengan kemasan kekinian kita meletakkan ajaran Islam sebagai ajaran rabbani. Islam sebagai agama wahyu, segala perundangundangannya datang dari yang maha mengetahui.

\section{Islam Agama Wahyu.}

Islam berbeda dengan agama-agama lain. Agama-agama selain Islam misal Zarathustra, Kristen, Yahudi, Hindu, dan Budha, hanya mempunyai sekup nasional. Agama-agama itu untuk kaum tertentu. Sementara agama Islam adalah agama yang mempunyai sekup 'alamiyah. Ke'alamiyah-an agama Islam adalah solid karena wawasan dan cakupan nilai yang ada dalam Islam sangat luas. Sehingga dapat merespon semua kecenderungan-kecenderungan yang ada. Nilai kekuatan Islam terletak pada sifatnya yang akomodatif terhadap perkembangan zaman dan perubahan tempat. Karena islam șāliḥ li kulli zamān wa makān. Dalam hal ini sayyid Sabiq, dalam fiqh sunnah-nya mengatakan:

"penetapan hukum Islam merupakan salah satu dari berbagai segi yang amat penting yang disusun oleh tugas suci Islam, dan yang memberi gambaran segi ilmiyah dari tugas itu. Penetapan hukum keagamaan murni, seperti hukum-hukum ibadah, tidak pernah timbul kecuali dari wahyu. Baik itu dari kitab, sunah, maupun ijtihad Nabi yang telah disetujui. Tugas Rasul tidak keluar dari lingkaran menyampaikan dan menjelaskan. Firman Allah:

$$
\text { وما ينطق عن الهوى ان هو إلا وحي يوحى }
$$

Artinya: "tidaklah ia (Nabi Muhammad) berbicara atas kemauan sendiri; tiada lain itu adalah wahyu yang diwahyukan kepadanya."3

\footnotetext{
${ }^{2}$ Muhammad Imarah, Abu A'la al-Maudūdi wa al-Sahwah al-Islāmiyah, (Kairo: Dār al- Syurūq, 1987), 73.

${ }^{3}$ QS. Al-Najm:3-4
} 
Adapun penetapan hukum yang berkaitan dengan perkara duniawi, seperti kehakiman, politik, peperangan, dan sebagainya, maka Rasul saw. diperintahkan untuk bermusyawarah. $^{4}$

Dengan meletakkan agama sebagai wahyu, maka kita telah meletakkan Islam sebagai agama kosmopolit. Karena wahyu mempunyai orientasi dan wawasan yang sangat luas. Orientasi dan wawasan wahyu digambarkan Ali Harb sebagimana luasnya bahasa dan peradaban. Semakin luas bahasa dan peradaban, maka semakin luas pula wawasan wahyu Qur'ani. ${ }^{5}$

Dengan meletakkan Islam sebagai agama wahyu, dan bukan sebagai ideologi, kosmopolitanisme agama Islam tampak; diakui bahwa dalam Islam terdapat banyak ideologi. Ada ideologi Sunni, Mu'tazili, Syi'i, dan lain sebagainya. Akan tetapi ideologi-ideologi itu hanya varian-varian kecil ( $\left.a j z a^{\prime}\right)$ dari cakupan Islam secara komprehensif. Ideologi-ideologi di atas adalah hasil olah pikir dan pencapaian dari eksperimen manusia, dengan meletakkan agama wahyu sebagai dasar pijakannya. Agama yang ajaran-ajarannya diformulasikan dalam Alquran dan Sunnah ${ }^{6}$ sangat kaya dengan nilai-nilai universal. ${ }^{7}$ Karena nilai universal itulah Islam bisa diterima semua orang.

\section{Islam Agama Kosmopolit.}

Kosmopolit atau kosmopolitan secara epistemologis berasal dari bahasa Yunani yaitu Kosmos dan Polites. Kosmos memiliki arti "alam semesta" atau "dunia" sementara Polites memiliki arti masyarakat atau "warga negara". 8 Maka kosmopolit atau kosmopolitanisme dapat diartikan sebagai sebuah keyakinan bahwa masyarakat di dunia sejatinya merupakan suatu kesatuan dalam sebuah tatanan politik-etis global berdasarkan asas kemanusiaan. Banyak unsur beragam yang disatukan tanpa menghilangkan garis besar perbedaannya. ${ }^{9}$

\footnotetext{
${ }^{4}$ Sabiq, al-Sayyid, Fiqh al-Sunnah, Vol. 1, (Kuwait: Dār al-Bayān, 1968), 17

${ }^{5}$ Ali Ḥarb, Naqd al-Haqiquah, Cet. I. (Beirut : al-Markaz al-Thaqāfi al- 'Arabi, 1993), 19

${ }^{6}$ Sabda Rasulullah SAW. :

${ }^{7}$ Ali Harb, Ibid.$$
\text { تركت فيكم امرين ما ان تمسكتم بهما من بعدي لن تضلوا ابدا، الكتاب وسنتي }
$$

${ }^{8}$ Gannaway, Adam, What is Cosmopolitanism?. (MPSA Conference Paper, 2009), 6.

${ }^{9}$ Ibid.
} 
Kosmopolitanisme Islam muncul dalam sejumlah unsur dominan, seperti hilangnya batasan etnis, kuatnya pluralitas budaya dan heterogenitas politik. Kosmopolitnisme itu bahkan menampakkan diri dalam unsur dominan yang menakjubkan, yaitu kehidupan beragama yang elektrik selama berabad-abad. Dan kalau kita mau telusuri, perdebatan sengit dibidang teologi dan hukum-hukum agama, akan tampak secara jelas betapa beragamnya pandangan yang dianut oleh kaum muslim waktu itu. Kalau pun hal itu dianggap sebagai kemelut kehidupan beragama kaum muslim, karena tidak adanya konsesus atas hal-hal dasar, maka harus juga dibaca dengan cara yang lain bahwa para pemikir muslim telah berhasil mengembangkan watak kosmopolitan dalam budaya dan keilmuan mereka, karena mampu berdialog secara terbuka dan bebas.

Kebebasan kaum Mu'tazilah untuk mempertanyakan kebenaran ajaran sentral Islam bahwa Alquran turun dalam bentuk huruf dan bahasa yang sekarang kita kenal (bahasa Arab dengan huruf hija'iyah) dan menganggap kitab suci kaum muslim tersebut diturunkan hanya secara maknawi belaka -sesuatu yang sekarang tentunya dianggap sikap seorang yang murtad dari agama Islam- adalah pertanda kuatnya watak kosmopolitan dari agama Islam. Pertanyaan bagaimanpun gilanya tetap mendapat peluang untuk diutarakan. ${ }^{10}$

Deskripsi-deskripsi di atas dapat memberikan gambaran akan luasnya wawasan Islam. Prinsip-prinsip dasar yang ada dalam Islam menunjukkan bahwa Islam adalah agama kosmopolit. Prinsip persamaan hak dan kewajiban adalah salah satu contoh. Dalam perspektif Islam tidak ada perbedaan antara kulit hitam dengan kulit putih, antara kaya dengan miskin, dan antara pejabat dengan rakyat. Islam tidak mengenal prinsip-prinsip deskriminatif, seperti yang dianut oleh agama lain. Dengan tegas Allah menegaskan bahwa manusia-manusia diciptakan terdiri dari bangsa-bangsa (syu'ub), etnis-etnis (qaba'il) agar mereka saling mengenal. Dan tidak ada yang lebih utama diantara mereka di sisi Allah kecuali yang lebih bertaqwa. ${ }^{11}$ Statemen diatas dikuatkan oleh Rasulullah. Dalam satu hadis berikut:

$$
\text { الناس سو اسية كأسنان المشط لا فضل لعربي على اعجمي إلا بالتقوى }
$$

\footnotetext{
${ }^{10}$ Abdurrahman Wahid, "Kebudayaan Islam yang Kosmopolit” dalam Nurcholis Madjid, Kontekstualisasi Doktrin Islam Dalam Sejarah, (Jakarta : Yayasan Paramadina, 1995) 548-550

${ }^{11}$ Al-Qur'an Surat al-Hujurat ayat 13, Allah berfirman: ياأيها الناس إنا خلقناكم من ذكر و انثى وجعلناكم شعوبا وقبائل لتعارفو ا ان اكرمكم عند الله اتقاكم ان الله عليم خبير
} 
Manusia diciptakan adalah sama; duduk sama rendah, berdiri sama tinggi, bagai gigi geruji alat sisir yang rata; tidak ada keutamaan orang arab atas 'ajam kecuali dengan taqwa. Islam tidak pernah dibatsi oleh warna kulit, tinggi atau rendahnya hidung, bukan pula oleh sekat-sekat geografis. Karena Islam adalah agama dunia, agama rahmatan bagi seluruh alam. ${ }^{12}$

Watak kosmopolitan Islam telah tampak sejak pertama kemunculannya. Dimulai dengan cara-cara Rasulullah mengatur pengorganisasian masyarakat Madinah hingga munculnya para ensiklopedis musim awal pada abad ketiga hijriyah, memantulkan proses saling menyerap dengan peradaban-peradaban yang lain di sekitar dunia Islam waktu itu, dari sisa-sisa peradaban Yunani kuno yang berupa Hellenisme hingga peradaban anak benua India.

\section{Fleksibilitas Agama Islam}

Al-Islām șālih li kulli zamān wa makān, itulah jargon santer yang sering sekali kita dengar, adagium itu bukan hanya semboyan klise belaka akan tetapi real. Sejarah telah mencatat berbagai kejadian besar dalam Islam, baik itu berupa pemikiran, kebudayaan, sosial ataupun politik. Terkodifikasinya berbagai disiplin ilmu Islam, terbentuknya berbagai bentuk aliran, dan sektarian, dibawah panji kebesaran Islam adalah manifestasi konkrit dari fleksibilitas agama Islam. Kotak-kotak (untuk menyebut banyaknya kelompok dan golongan) itu pasti ada, di mana dan dalam hal apa saja, masalahnya sekarng bukan kotak itu sendiri, tapi bagaimana kotak-kotak itu bisa saling eksis, saling mengisi, saling asah, saling asuh, saling asih; bagaiman kita tidak terjebak dalam fanatisme kotak yang sempit. Untuk itu diperlukan wawasan yang luas. Islam dengan nilai fleksibilitasnya, dalam sepanjang sejarah telah berhasil menaungi semua varianvarian kotak itu. Hanya kotak sering menjebak seseorang kearah fanatisme sempit, akhirnya terjadilah baku hantam yang sangat disesalkan. Dalam hal ini Dr. Mustafa Syakh'ah mengatakan:

Islam istimewa karena nilai fleksibikitasnya (murunah) yang bisa mencakup kecenderungan-kecenderungan basyariyah. Kalau dalam perjalanan sejarahnya,

\footnotetext{
${ }^{12}$ Firman Allah:
} 
Islam sering dikecam jumud, sempit, fanatik, itu bukan berarti dosa Islam, tapi dosa orang-orang konserfatif yang membawa Islam,. 13

Dengan menanam dan menggali nilai fleksibilitas itu, kehidupan beragama akan terasa dinamis, dengam demikian terciptalah proses simbiosis mutualis antara varian-varian itu yang sangat kita idam-idamkan.

Syaikh Muhmud Syaltut, Grand syeh al-Azhar tempo dulu, menjelaskan bahwa lembaga institusi Islam yang telah merinitis kearah itu adalah Universitas al-Azhar, dengan diterapkannya kajian-kajian disiplin ilmu agama dari berbagai aliran, meski dengan versi yang berbeda-beda. ${ }^{14}$

\section{Heterogenitas Visi Islam}

Sebagai dampak dari fleksibility yang dimiliki Islam, adalah munculnya beberapa paham dan aliran praktis keagamaan, seperti yang telah disinggung diatas. Nilai universal yang terkandung dalam wahyu Qur'ani melahirkan beberapa interpretasi tentang wahyu itu sendiri. Dari sini lahirlah heterogenitas dan pluralitas visi keagamaan, sesuai dengan disiplin keilmuan masing-masing. Dalam skala makro, heterogenitas visi keagamaan itu dibagi Sa'id Hawwa dalam dua kelompok besar: Fiqh al-Kabir, dan Fiqh al-Akbar. Fiqh al-Kabir mencakup ilmu fiqh itu sendiri, qawa'id dan usulnya. Sementara Fiqh al-Akbar meliputi aqidah (teologis) dan tasawuf. ${ }^{15}$ masing-masing disiplin ilmu itu mempunyai tokoh-tokoh yang cukup mewakili.

\section{Stagnasi Dalam Islam}

Banyak pengamat mengatakan bahwa stagnasi pemikiran keislaman terjadi pada abad keenam sampai ketiga belas Hijriyah. Pemikiran fiqih mengalami kemunduran dimulai kemandegan dan diakhiri kebekuan. Pada masa itu pemikiran taqlid menjadi dominan, pemahaman berubah dari upaya mencari sebab-sebab dan maksud syara' ke upaya menghafal yang sering sia-sia lantaran tanpa analisa. Orang merasa sudah merasa cukup dengan yang sudah tertulis dalam kitab-kitab madzhab tanpa penelitian. Orientasi ini telah membunuh kreatifitas

\footnotetext{
${ }^{13}$ Musthafa Syakh'ah, “Islam Bila Mąāhib”, (Kairo: Dar al-Misriyah al-Libnaniyah), 47

${ }^{14}$ Mahmud Shaltut, Ibid. 26

${ }^{15}$ Sa'id Hawwa, Jaulat Fi al-Fiqhain al-Kabir wa al-Akbar, (Kairo : Muassasah, al-Khalij al- 'Arabi, 1988), 11
} 
akal yang dulunya pernah jaya dengan gerakan takhrij dan tarjih. Pengkajian fikih umum yang dikaji kitab-kitab fikih tertentu. Dampak yang sangat mencolok adalah lahirnya budaya fanatisme Madzhab.

Masa kemandegan itu ditandai dengan gerakan-gerakan tadwin, mensyarah, dan menhasyiyah. Orang hanya mereferensi kitab-kitab yang telah terkodifikasi itu, tanpa lagi mencari sebab akibat yang terjadi setelah hukum. Pada satu sisi, memang gerakan tadwin, syarah dan hasyiyah bisa menginventarisir hazanah keilmuan Islam, tapi pada sisi lain menyebabkan orang puas dan bangga dengan yang telah dicapai para pendahulu. Mereka hanya bisa bangga dengan sejarah besar itu, tapi bagaimana supaya mereka dapat menciptakan sejarah besar itu tanpa dilakoni. Akibatnya mereka hanya berputar di tempat tanpa menghasilkan apapun.

Sudah saatnya kita ini melakukan gerakan-gerakan baru yang akan menciptakan sejarah besar baru. Sarana untuk menuju kearah itu sangat memungkinkan bila dibandingkan dengan para pendahulu kita menciptakan sejarah besar. Kalau faktor IQ barang kali yang menjadi kendala, -meskipun ungkapan ini sama sekali tidak beralasan- maka kita adakan kaderisasi bibit unggul IQ unggulan. Pintu ijtihad yang tidak pernah tertutup, sebagaimana tidak pernah tertutupnya problem umat, adalah medan untuk berolah otak dan berolah fikir. Dari situlah kebangkitan Islam senantiasa diharapkan.

\section{Solusi Deradikalisasi Memupuk Sikap Toleransi}

Pemahaman tentang Islam sebagai agama kosmopolit merupakan usaha untuk menempatkan Islam dan umat muslim agar bisa hidup dan berkembang dengan dijiwai oleh semangat toleransi dan saling menghormati antar sesama dan sekaligus dapat menjaga hidup bersama dalam rangka menjaga kedaulatan negara.

Dengan mengembangkan pemikiran Islam sebagai agama kosmopolit ini pula diharapkan bisa menjadi terapi atas terbendungnya gerakan radikal yang sering muncul dan termotivasi oleh pemahaman ajaran agama Islam yang sempit.

\section{Penutup.}


Islam adalah agama fitrah, sejalan dengan karakter manusia. Kecenderungankecenderungan untuk kembali ke agama fitrah sudah tampak dimana-mana. Suara șậwah (kebangkitan) kita dengar di mana-mana dengan macam-macam versinya. Menjelang kebangkitan Islam yang kita idam-idamkan perlu adanya kesiapan yang matang. Kebangkitan yang kurang seimbang dengan persiapan akan menciptakan problem-problem lebih besar. Kebangkitan harus berjalan secara evolutif agar dapat mengakar selama-lamanya.

Lonatran-lontaran pemikiran yang dituangkan dalam tulisan ini dimaksudkan sebagai perangsang untuk menggali persiapan kebangkitan. Islam sebagai agama besar harus kita letakkan pada proporsi kebesarannya. Wawasan luas, keilmuan tinggi akan dapat membawa Islam sesuai dengan kebesarannya, semoga kita dapat mengemban amanat Islam membawa panji-panjinya keseluruh alam raya. Amiin

\section{Daftar Pustaka}

Alquran al-Karim

Ali Harb, Naqd al-Haqiquah, Beirut: Al-Markaz al-Thaqafi al-'Arabi, Cet. I. 1993.

Gannaway, Adam, What is Cosmopolitanism?. (MPSA Conference Paper, 2009.)

Mahmud Syaltut, "Kata Pengantar", dalam Musthafa al-Syakh'ah, "Islam Bila Mazāhib”, Kairo: Dar al-Misriyah al-Libnaniyah. 1994.

Muhammad Imarah, Abu A'la al-Maudūdi wa al-Ṣạwah al-Islāmiyah, Kairo: Dar al-Syuruq, 1987.

Musthafa Syakh’ah, “Islam Bila mazāhib”, Kairo, Dar al-Misriyah al-Libnaniyah. Cet. X 1994.

Nurcholis Madjid, Kontekstualisasi Doktrin Islam Dalam Sejarah, Jakarta : Yayasan Paramadina, 1995.

Sa'id Hawwa, Jaulat Fi al-Fiqhain al-Kabir wa al-Akbar, Kairo: Muassasah, al-Khalij al-'Arabi, 1988.

Sabiq, al-Sayyid, Fiqh al-Sunnah, Kuwait: Dar al-Bayān, Vol. I, 1968. 